\title{
Desenvolvendo as CAPACIDAdes DE linguagem NA PRODUÇÃO DO GÊNERO DE HISTÓRIA EM QUADRINHOS (HQs)
}

\author{
DEVELOPING THE LANGUAGE SKILLS IN THE PRODUCTION OF THE \\ COMICS GENRE (COMICS)
}

DOI: http://dx.doi.org/10.23926/RPD.2526-2149.2018.v3.n2.p437-444.id224

\author{
Thiago Silva e Silva \\ Mestre em Letras \\ (UNIFESSPA). \\ Professor de Língua \\ Portuguesa da rede \\ municipal de Barra do Corda \\ - MA. \\ thiago.silva@ifma.edu.br
}

\section{Áustria Rodrigues \\ Brito}

Doutora em Linguística

(UnB).

Professora Ajunta da

Universidade Federal do Sul

e Sudeste do Pará

(UNIFESSPA).

austria@unifesspa.edu.br
Resumo: Com ênfase no desenvolvimento das capacidades de linguagem requeridas no momento de produção de um texto, o presente artigo pretende analisar, quantitativa e qualitativamente, os avanços nas produções textuais no gênero história em quadrinhos (HQs), de doze alunos da $8^{\mathrm{a}}$ série, turma vespertina, de uma escola municipal de Barra do Corda - MA, as quais foram produzidas pelos referidos discentes durante a pesquisa realizada, entre agosto e dezembro de 2016, no âmbito do Programa de Mestrado Profissional em Letras (PROFLETRAS), ofertado pela Universidade Federal do Sul e Sudeste do Pará (UNIFESSPA). Tal pesquisa, embasada nos estudos teóricos de Bakhtin (2011), Gonçalves (2010), Mendonça (2010), Dolz, Noverraz e Schneuwly (2004), entre outros, aplicou uma Sequência Didática (SD) elaborada a partir das dificuldades dos alunos partícipes da pesquisa identificadas na produção inicial (T1), onde ao longo da SD, foram propostas, após a execução dos módulos que a compunham, mais duas reescritas da T1. As análises aqui presentes indicam que, após as intervenções, houve avanço substancial na produção textual dos alunos pesquisados no tocante às capacidades de ação, discursivas e linguístico-discursivas.

Palavras-chave: Capacidades de linguagem. História em quadrinhos. Produção textual.

\begin{abstract}
With the emphasis on the development of the language abilities required at the time of producing a text, this article intends to analyze, quantitatively and qualitatively, the advances in the production of texts in the genre comics (HQs), of twelve students of the 8th grade, which were produced by the mentioned students during the survey conducted between August and December 2016, within the scope of the professional master 's program in Literature (PROFLETRAS), offered by Federal University of Southern and Southeastern Pará (UNIFESSPA). This research, which was based on the theoretical studies of Bakhtin (2011), Gonçalves (2010), Mendonça (2010), Dolz, Noverraz and Schneuwly (2004), among others, applied a Didactic Sequence students who participated in the research identified in the initial production (T1), where they were proposed, after the execution of the modules that composed it, two more rescripts of $\mathrm{T} 1$. The present analyzes indicate that, after the interventions, there was a substantial advance in the textual production of the students researched in terms of the capacities of action, discursive and linguistic-discursive.
\end{abstract}

Keywords: Language skills. Comic books. Text production. 
Revista Prática Docente - RPD

Confresa-MT. Volume 3. Número 2. Julho/Dezembro 2018.

\section{INTRODUÇÃo}

O uso do gênero de História em Quadrinhos, doravante denominado HQs, como recurso metodológico, em especial, no ensino da língua materna é recente, considerando que até a década de 90 havia uma massiva marginalização do seu uso, ao ponto de aqueles que lessem textos desse gênero receberem o rótulo de cidadãos desajustados. Após esse período, as HQs começam a ganhar espaço na sala de aula, devido, entre outros fatores, ao relativo abandono da posição que considera a língua sob a ótica de uma estrutura pronta e estanque. Nesse cenário de mudanças de concepção, a língua passa a ser entendida como fenômeno social e dialógico.

Dessa forma, a língua não é estática, mas viva e interativa, contrariando aqueles que a tem apenas como um sistema abstrato, desconexa das práticas sociais e que concebem sua aprendizagem somente pela transmissão de estruturas rígidas. Com essas mudanças, ganhou espaço a proposta de que um estudo das línguas seria mais consistente e mais relevante se elegesse, como ponto de referência, o texto.

Rojo (2005, p. 18) ratifica a importância de que as situações de ensino da língua precisam ser organizadas, basicamente, considerando-se a diversidade de textos e gêneros que circulam socialmente, bem como as suas características específicas.

Esse mesmo posicionamento está gravado nas orientações contidas nos Parâmetros Curriculares Nacionais (PCN), em que é possível perceber que os mesmos foram fortemente influenciados pela teoria da linguagem como processo interativo e social. Em virtude disso, essa peça oficial aponta o texto e seus diversos gêneros como "pontos de partida" para que se aprenda sobre linguagem.

Nesse sentido, os PCN (1997, p. 25), primeira parte, expressam que a escola terá que promover uma revisão substantiva das práticas de ensino que tratam a língua como algo sem vida e os textos como conjunto de regras a serem aprendidas, bem como a constituição de práticas que possibilitem ao aluno aprender linguagem a partir da diversidade de textos que circulam socialmente, para que se atenda a essa nova demanda.

Ainda nessa esteira, Marcuschi (2008, p. 51) informa que o ensino da Língua Portuguesa "através de textos é hoje um consenso tanto entre linguistas teóricos como aplicados. Sabidamente, essa é, também, uma prática comum na escola e orientação central dos PCN".

Por outro lado, observamos que há um descompasso entre o que é dito e os resultados alcançados, a julgar pelos insucessos no ensino de Língua Portuguesa quando o assunto é produção textual. À guisa do exemplo, no Exame Nacional do Ensino Médio (ENEM) de 2017, 
Revista Prática Docente - RPD

Confresa-MT. Volume 3. Número 2. Julho/Dezembro 2018.

segundo a reportagem veiculada, em 18/01/2018, pelo jornal on-line O Globo ${ }^{1}$, houve um aumento substancial das redações com nota zero em relação à edição de 2016. Segundo a matéria, no ENEM de 2017, 309.157 candidatos receberam nota zero na prova de redação, e destes, a esmagadora maioria a tiram porque fugiram do tema. Esses dados confirmam a conclusão a que chegamos no início deste parágrafo.

Considerando todas as orientações e posicionamentos teóricos, e ainda as dificuldades que a maioria dos discentes brasileiros possuem para produzirem textos coesos e coerentes, o presente artigo pretende analisar, quantitativa e qualitativamente, os avanços na produção dos textos no gênero HQs, de doze alunos da $8^{\mathrm{a}}$ série $^{2}$, turma vespertina, de uma escola municipal de Barra do Corda - MA, com ênfase no desenvolvimento das capacidades de linguagem requeridas no momento de produção de um texto. Informamos que essas produções foram realizadas pelos discentes no decorrer da pesquisa realizada, entre agosto e dezembro de 2016, no âmbito do programa de Mestrado Profissional em Letras (PROFLETRAS), ofertado pela Universidade Federal do Sul e Sudeste do Pará (UNIFESSPA). Além disso, as análises aqui expressas se dedicarão apenas a uma parte da pesquisa original feita durante o mestrado.

Apesar de a referida pesquisa ter sido aplicada em uma local específico, ela possui grande relevância, seja porque as orientações oficiais e o arcabouço teórico orientam que é necessária a adoção dos gêneros textuais nas aulas de Língua Portuguesa, o que nos parece muito promissor e exequível; seja pela possibilidade de apontarmos, a partir dos resultados alcançados, caminhos possíveis - não fórmulas fechadas - que podem levar à resolutividade de um problema que perpassa os limites geográficos do município barra-cordense, isto é, de proporção nacional.

\section{REFERENCIAL TEÓRICO}

Com uma abordagem baseada no Interacionismo Sócio-Discursivo (ISD), Dolz e Schneuwly (2004, p.44) nos informam que as capacidades de linguagem, ou capacidades verbais, requeridas pelo aprendiz no momento de produção de um gênero textual numa situação de interação são: a) capacidades de ação que se referem à capacidade de adaptar-se às características do contexto e do referente, b) capacidades discursivas que se relacionam à

1 https://oglobo.globo.com/sociedade/educacao/enem/enem-2017-registra-aumento-de-redacoes-com-nota-zero22300924 Acesso em: 09 de jun. de 2018, às 23h22min.

${ }^{2}$ Corresponde ao $9^{\circ}$ ano do Ensino Fundamental. 
Revista Prática Docente - RPD

Confresa-MT. Volume 3. Número 2. Julho/Dezembro 2018.

mobilização de modelos discursivos e c) capacidades linguístico-discursivas que abrangem o domínio das operações psicolinguísticas e das unidades linguísticas.

A partir desse espectro, Gonçalves (2010, p. 50) nos diz que as capacidades de ação são as representações que o produtor de texto faz ou deve fazer para adaptar sua produção, oral ou escrita, às características do contexto e do referente. De outro modo, podemos sintetizar o conceito aqui transcrito com a afirmação de que as escolhas/representações feitas pelo produtor levam em conta, pelo menos, dois aspectos: o meio físico (o qual denominaremos de contexto físico), que é o lugar e o momento de produção, e o meio subjetivo (contexto sociossubjetivo), da interação de fato, onde o papel social dos interlocutores, a instituição social de onde falam e os objetivos sociocomunicativos interferem diretamente no processo interlocutivo.

Concernente às capacidades discursivas, entendemos que após as escolhas/representações, o produtor articulará, nessa fase, de forma concomitante, o plano geral do texto, os tipos de discursos (ou gêneros textuais) e os tipos de sequências (ou tipologia textual). No caso das HQs, o texto verbal encontra-se sempre dentro de balões ${ }^{3}$; os desenhos devem estar em perfeita sintonia com o texto escrito, a fala do narrador, quando há a presença do mesmo, normalmente se localiza em um retângulo; quanto às sequências textuais, as HQs são predominantemente narrativas, contudo, dada a heterogeneidade tipológica, comum a todos os gêneros, podemos encontrar nesse gênero sequências dialogal, injuntiva e argumentativa, sendo as duas últimas menos frequentes. As cenas encontram-se dentro de um quadro (vinheta) e podem ter formatos diferentes.

Por derradeiro, temos as capacidades linguístico-discursivas, que são as operações linguísticas ligadas à produção de qualquer texto, as quais mobilizam os elementos da textualização (Coesão e Coerência), os mecanismos enunciativos (vozes e modalizações), as operações de construção dos enunciados e as escolhas lexicais.

O conceito de capacidades de linguagem está em perfeita harmonia com o de gênero textual na perspectiva bakhtiniana: "tipos relativamente estáveis de enunciado" (BAKHTIN, 2011, p. 262). Nesse sentido, qualquer que seja o gênero textual, ele não se apresenta como um artefato sem vida, isto é, inerte; pelo contrário, ele evolui e acompanha as necessidades sociocomunicativas dos diversos campos da atividade humana.

\footnotetext{
${ }^{3}$ Segundo Mendonça (2010, p. 2010), inicialmente os textos verbais vinham escritos no rodapé do desenho, depois passou a ser junto aos personagens e por fim, tal como conhecemos hoje, os textos são grafados nos balões. 
Essa noção de gêneros textuais é imprescindível para o sucesso do processo de ensino e aprendizagem de produção textual, oral ou escrita, haja vista que toda produção sempre se corporificará através de um dos diversos gêneros textuais; e não é somente a forma que os determina, mas, e sobretudo, a sua função sociocomunicativa.

Ancorados nesses conceitos, concluímos que o "como dizer" e "o que dizer" dependem do "para quem dizer", ou seja, o usuário da língua terá que se adaptar às características do contexto e do referente (capacidades de ação); o "como dizer" se corporifica sempre em um gênero textual (capacidades discursivas), e ainda, que, dependendo do "para que dizer" e de "o que dizer", é necessário mobilizar conhecimentos linguísticos (capacidades linguísticodiscursivas).

\section{Metodologia da Pesquisa}

Inicialmente, realizamos um estudo teórico minucioso acerca do gênero HQs, a fim de evidenciarmos as dimensões ensináveis desse gênero e mapear as capacidades de linguagem que poderiam ser exploradas na sua produção. A elaboração desse levantamento prévio denomina-se Modelo Didático do Gênero (MDG), que é uma etapa antecessora à construção da Sequência Didática (SD). Em suma, Gonçalves (2010, p. 95) ao citar os autores genebrinos Dolz, e Schneuwly (2004) diz que o MDG constitui uma síntese prática destinada a orientar as intervenções dos professores e evidencia as dimensões ensináveis do gênero.

Como resultado desse levantamento prévio, apresentamos abaixo um quadro sinótico do MDG das HQs, em que relacionamos as características gerais observadas do gênero HQs com as respectivas capacidades verbais.

Quadro 1 - Síntese do MDG de HQs

\begin{tabular}{|c|l|}
\hline Capacidades Verbais & \multicolumn{1}{|c|}{ Características do Gênero HQs } \\
\hline \multirow{5}{*}{ Capacidades de Ação } & - Os textos circulam, principalmente, em revistas, livros (retextualizações \\
de clássicos da literatura), jornais e na internet. Esses textos podem ser \\
reunidos em gibis infantis (Cebolinha, por exemplo) e adultos, \\
Almanaques (dedicados a um grupo de personagens) livros, como a \\
Mafalda. \\
Contextos Físico e & - Os escritores desse gênero são chamados quadrinistas. \\
Sociossubjetivo de Produção & alcançado do público infantil ao idoso, devido, principalmente, à \\
& variedade temática que elas abordam. \\
& - Sua produção pode se dar, principalmente, nas instâncias discursivas dos \\
& discursos jornalístico, literário e publicitário. \\
& - Dependendo do meio em que são produzidas, as HQs objetivam, por \\
& exemplo, o entretenimento e o convencimento (nas campanhas \\
& publicitárias). \\
\hline
\end{tabular}




\begin{tabular}{|c|c|}
\hline Capacidades Discursivas & $\begin{array}{l}\text { - Predominam as sequências textuais narrativa e dialogal. } \\
\text { - O discurso direto é mais recorrente. } \\
\text { - Os textos são colocados dentro de balões. O formato do balão indica } \\
\text { uma finalidade específica. } \\
\text { - O formato da letra informa, além do significado da palavra, outras } \\
\text { mensagens, como por exemplo, grito. } \\
\text { - A compreensão das histórias se dá através da interação de códigos } \\
\text { verbais e não-verbais. } \\
\text { - O formato mais adequado de quadro ou vinheta a se utilizar em uma } \\
\text { determinada história dependerá do objetivo ou ação que se pretende } \\
\text { realçar. A utilização de vinhetas de tamanhos diferentes na mesma } \\
\text { página facilita a leitura da história, afastando a monotonia visual. } \\
\text { - As linhas que demarcam o contorno das imagens que forma os } \\
\text { quadrinhos trazem informações substanciais ao leitor. Linhas contínuas } \\
\text { ou sólidas indicam que a ação retratada ocorre no mundo real. Alguns } \\
\text { autores, devido à plasticiade do gênero, preferem nem utilizar a linha } \\
\text { demarcatória separando os quadrinhos. }\end{array}$ \\
\hline $\begin{array}{c}\text { Capacidades Linguístico- } \\
\text { Discursivas }\end{array}$ & $\begin{array}{l}\text { - Uso abundante dos pronomes pessoais de } 1^{\mathrm{a}} \text { e } 2^{\mathrm{a}} \text { pessoas do singular. } \\
\text { - Uso abundante de reticências, indicando omissão de fala, o que dá ao } \\
\text { leitor possibilidade de criar e/ou imaginar. } \\
\text { - A entonação das falas dos personagens é marcada, constantemente, } \\
\text { pelo uso dos pontos de exclamação e interrogação. } \\
\text { - É comum o uso de interjeições (expressão do "estado de espírito" dos } \\
\text { personagens). } \\
\text { - Emprego da elipse, não somente restrita a uma única palavra. } \\
\text { - Emprego das onomatopeias e metáforas verbais e visuais. } \\
\text { - Utilização de frases interrogativas, afirmativas, frases longas, curtas, } \\
\text { frases incompletas. } \\
\text { - Utilização da linguagem formal e informal, a depender do personagem- } \\
\text { tipo e do contexto em que ele está inserido; } \\
\text { - Grande variedade de tempo verbal. }\end{array}$ \\
\hline
\end{tabular}

Fonte: Arquivo dos pesquisadores (2016).

Após a confecção do MDG, construímos a SD a partir da produção inicial (T1) dos alunos envolvidos na pesquisa e seguindo o modelo proposto por Dolz, Noverraz e Schneuwly (2004, p. 82), os quais a definem como "conjunto de atividades escolares organizadas, de maneira sistemática, em torno de um gênero textual oral ou escrito". A seguir, apresentamos o esquema da SD proposta pelos autores e a que de fato aplicamos em sala de aula.

Quadro 2 - Esquema da Sequência Didática

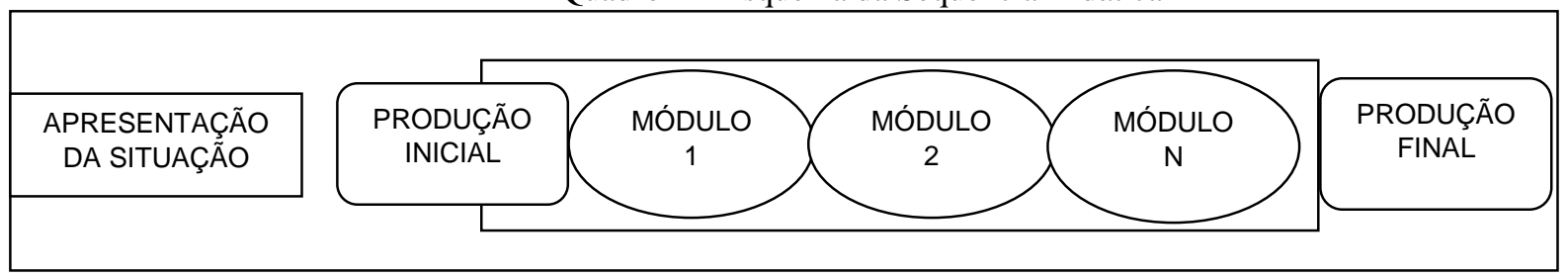

Fonte: Dolz, Noverraz e Schneuwly (2004, p. 83) 
Quadro 3 - Síntese da SD aplicada em sala de aula

\begin{tabular}{|l|}
\hline \multicolumn{1}{|c|}{ ETAPA } \\
\hline APRESENTAÇÃO DA SITUAÇÃO \\
- Apresentação do projeto aos alunos e seus respectivos pais/responsáveis. \\
- História das HQs, principais personagens; principais quadrinistas; alguns elementos composicionais das HQs \\
e distribuição de livros e revistas para leitura. \\
- Conhecendo os softwares Hagaquêt e Pixton \\
\hline PRODUÇÃO INICIAL (T1) \\
- Temática Livre. \\
- Correção da T1 \\
\hline MÓDULO 1 \\
- Formatos dos balões, letreiros, ordem dos quadros, enquadramento, planos e ângulos e figuras cinéticas. \\
- (T2) Reescrita da Produção Inicial. \\
\hline MÓDULO 2 \\
- Figuras de Linguagem nas HQs. \\
- Socialização das leituras realizadas em casa. \\
- Entrega das correções da T2. \\
\hline MÓDULO 3 \\
- A pontuação na construção dos sentidos. \\
\hline MÓDULO 4 \\
- Mecanismos de Textualização. \\
- Sequência narrativa. \\
- Socialização das leituras realizadas em casa. \\
\hline PRODUÇÃO FINAL (T3) \\
- Produção do texto (guiões ou scripts). \\
- Produção dos desenhos com base nos textos produzidos. \\
- Vetorização das HQs utilizando a plataforma Pixton. \\
\hline
\end{tabular}

Fonte: Arquivo dos pesquisadores (2016).

Após etapa de apresentação da situação, propomos aos estudantes a produção de um pequeno texto, de no máximo dez quadrinhos, com temática livre, no gênero textual de HQs. Inicialmente, eles produziram os scripts e só depois foram ao laboratório de informática realizar a vetorização no programa computacional Hagaquê.

Depois, efetuamos as análises das produções, procurando identificar o que deveria ser objeto de estudo nos módulos da SD. Retornamos à sala de aula com os textos e com as correções feitas por nós. Acertamos que os alunos apresentariam oralmente seus textos, para que cada colega pudesse contribuir para melhoria do texto do outro. À medida que um aluno apontava uma contribuição, nós apontávamos outra, com base nas constatações prévias, e assim nos revezamos. Além disso, cada estudante tinha também a oportunidade de defender o que escreveu.

\footnotetext{
${ }^{4}$ É um software educativo gratuito de apoio à alfabetização e ao domínio da linguagem escrita. É bastante utilizado para a produção de textos no gênero HQs. Disponível em: http://www.nied.unicamp.br/?q=content/hag\%C $3 \% \mathrm{Alqu} \% \mathrm{C} 3 \% \mathrm{AA}$

${ }^{5}$ É uma plataforma paga que oferece o serviço online para a criação de quadrinhos. Disponível em: https://www.pixton.com/br/
} 
Revista Prática Docente - RPD

Confresa-MT. Volume 3. Número 2. Julho/Dezembro 2018.

Nas palavras de Dolz, Noverraz e Shneuwly (2004, p. 86) "no momento da produção inicial, os alunos tentam elaborar um primeiro texto oral ou escrito e, assim, revelam para si mesmos e para o professor as representações que têm dessas atividades". Assim sendo, percebemos o caráter formativo que deve assumir a avaliação dessa produção, pois ela é na verdade um ponto de partida capaz de revelar o que precisa ser aprimorado e acrescentado de conhecimento.

Os critérios adotados para avaliação/correção/intervenção dos/nos textos foram norteados pelas capacidades de linguagem. A fim de facilitar esse processo de intervenção nas produções textuais, criamos um quadro com perguntas-guia, inspirados nas lições de Adair Vieira Gonçalves, em Gonçalves (2010), conforme segue:

Quadro 4 - Perguntas-guia ${ }^{6}$ utilizadas para a correção dos textos

\begin{tabular}{|c|c|}
\hline $\begin{array}{l}\text { Questões Relativas ao } \\
\text { Contexto de Produção }\end{array}$ & $\begin{array}{l}\text { - Ficaram claros os objetivos de comunicação? } \\
\text { - Há adequação do texto em função do suporte (Mural da Escola)? } \\
\text { - O que está no texto pode ser facilmente compreendido pelo público-alvo } \\
\text { (inicialmente os alunos do } 6^{\circ} \text { ao } 9^{\circ} \text { ano da escola CAIC)? Está adequado, } \\
\text { considerando o público-leitor? }\end{array}$ \\
\hline $\begin{array}{c}\text { Questões Relativas à } \\
\text { organização geral do texto }\end{array}$ & $\begin{array}{l}\text { - Há narrador? Se não, como ocorre a progressão da história? } \\
\text { - O foco narrativo foi seguido, isto é, o narrador continua no mesmo tipo de } \\
\text { abordagem? } \\
\text { - As ações (gestos, expressões corporais) e falas estão se relacionando com a } \\
\text { voz do narrador? } \\
\text { - O texto apresenta os elementos básicos (narrador, enredo, personagens, } \\
\text { tempo e espaço) e a estrutura (Apresentação, Desenvolvimento, Clímax e } \\
\text { Desfecho) de uma narrativa? } \\
\text { - Há diálogos? Que tipo discurso utiliza? } \\
\text { - Utiliza corretamente os balões? } \\
\text { - Utiliza corretamente os elementos do gênero? } \\
\text { - Os textos verbais estão em sintonia com o texto imagético? } \\
\text { - O título desperta a curiosidade do leitor? }\end{array}$ \\
\hline $\begin{array}{l}\text { Questões relativas à } \\
\text { textualização }\end{array}$ & $\begin{array}{l}\text { - Utiliza as interjeições com o intuito de expressar os aspectos emocionais das } \\
\text { personagens? } \\
\text { - Utiliza corretamente as onomatopeias? } \\
\text { - Faz escolhas nominais (substantivos e adjetivos) adequadas? } \\
\text { - Os textos possuem coesão nominal e verbal? } \\
\text { - Respeita às normas da Gramática Normativa (Ortografia, concordância, } \\
\text { morfossintaxe, etc.)? }\end{array}$ \\
\hline
\end{tabular}

Fonte: Arquivo dos pesquisadores (2016)

Nos módulos da SD, os conteúdos trabalhados neles foram resultados das constatações observadas na primeira produção textual (T1).

\footnotetext{
${ }^{6}$ Essas perguntas-guia embasaram as correções da T1, T2, e T3. 
Revista Prática Docente - RPD

Confresa-MT. Volume 3. Número 2. Julho/Dezembro 2018.

\section{Resultados}

As análises apresentadas versarão somente sobre as produções textuais T1, T2 e T3, com foco no desenvolvimento das capacidades de linguagem, apesar de a pesquisa em que se baseia este artigo permitir discussões sobre muitos outros aspectos, haja vista a sua extensão e complexidade.

\subsection{ANÁlISE DAS PRODUÇÕES T1}

Neste artigo, das doze produções iniciais (T1), apresentaremos, a título de exemplo, apenas duas delas, contudo, as análises e discussões se darão sobre a totalidade.

Figura $1-\mathrm{T} 1$ do aluno $\mathrm{A} 1^{7}$
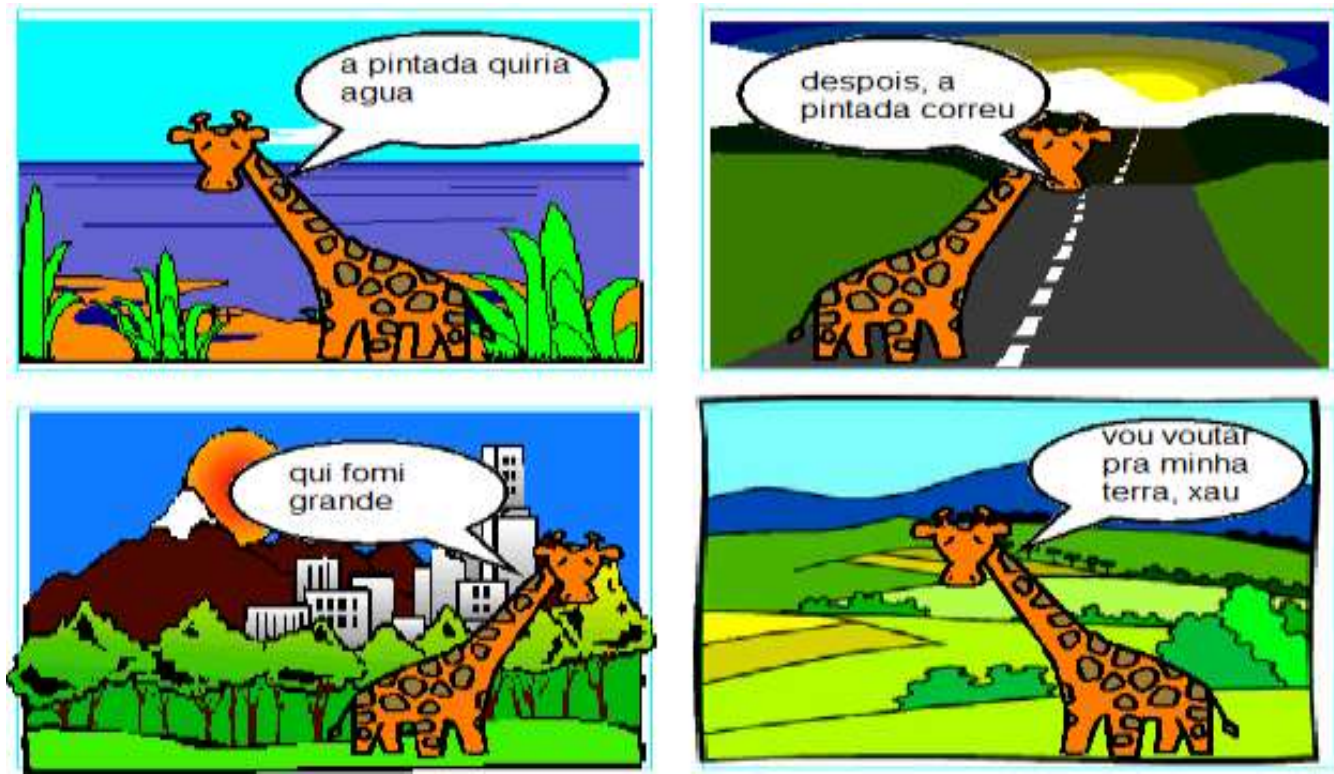

Fonte: Arquivo dos pesquisadores (2016)

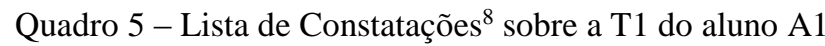

- Não há contextualização prévia da história.

- O aluno não consegue atrair a atenção do público leitor.

- O texto não apresenta os elementos (narrador, enredo, por exemplo) e nem contempla a estrutura

(Apresentação, Desenvolvimento, Clímax e Desfecho) de uma narrativa

- A fala do narrador se confunde com a fala da personagem ( $1^{\circ}$ e $2^{\circ}$ quadrinhos $)$.

- Não há a presença de narrador, ou se tem não é nítida a sua presença.

- Os balões não são usados corretamente (nem na ficha nem na versão vetorizada).

- A história possui título apenas na versão escrita na ficha/roteiro.

- O título precisa ser reescrito a fim de se tornar mais atraente.

- Não há figuras de linguagem.

- A sintonia entre o texto e as imagens é parcial, devendo ser melhorada.

- Pouquíssimos quadrinhos.

- Precisa melhorar o desfecho (final) da história.

\footnotetext{
${ }^{7}$ A fim de preservar a identidade dos alunos participantes da pesquisa, foram atribuídos códigos.

${ }^{8}$ Essas listas de constatações são as mesmas a que os alunos tiveram acesso e, por isso, serão apresentadas dentro de quadros.
} 
- Utiliza corretamente os verbos na fala das personagens.

- Emprega corretamente a coesão do tipo por substituição. Ex.: O pronome ele, no $3^{\circ}$ quadrinho, em substituição à palavra Jorginho.

- As cenas dos quadrinhos não são coesas, por isso, sugerimos a inserção da fala do narrador para indicar a passagem de uma cena para a outra.

- Ausência de elementos coesivos, principalmente os de substituição a fim de evitar repetição.

- Há problemas sérios de ortografia e de pontuação. Por outro lado, alguns deles deram-se em virtude de dificuldades para digitar.

Fonte: Arquivo dos pesquisadores (2016).

Figura 2 - T1 da aluna B1 CRIE SUA HQ AQUI!

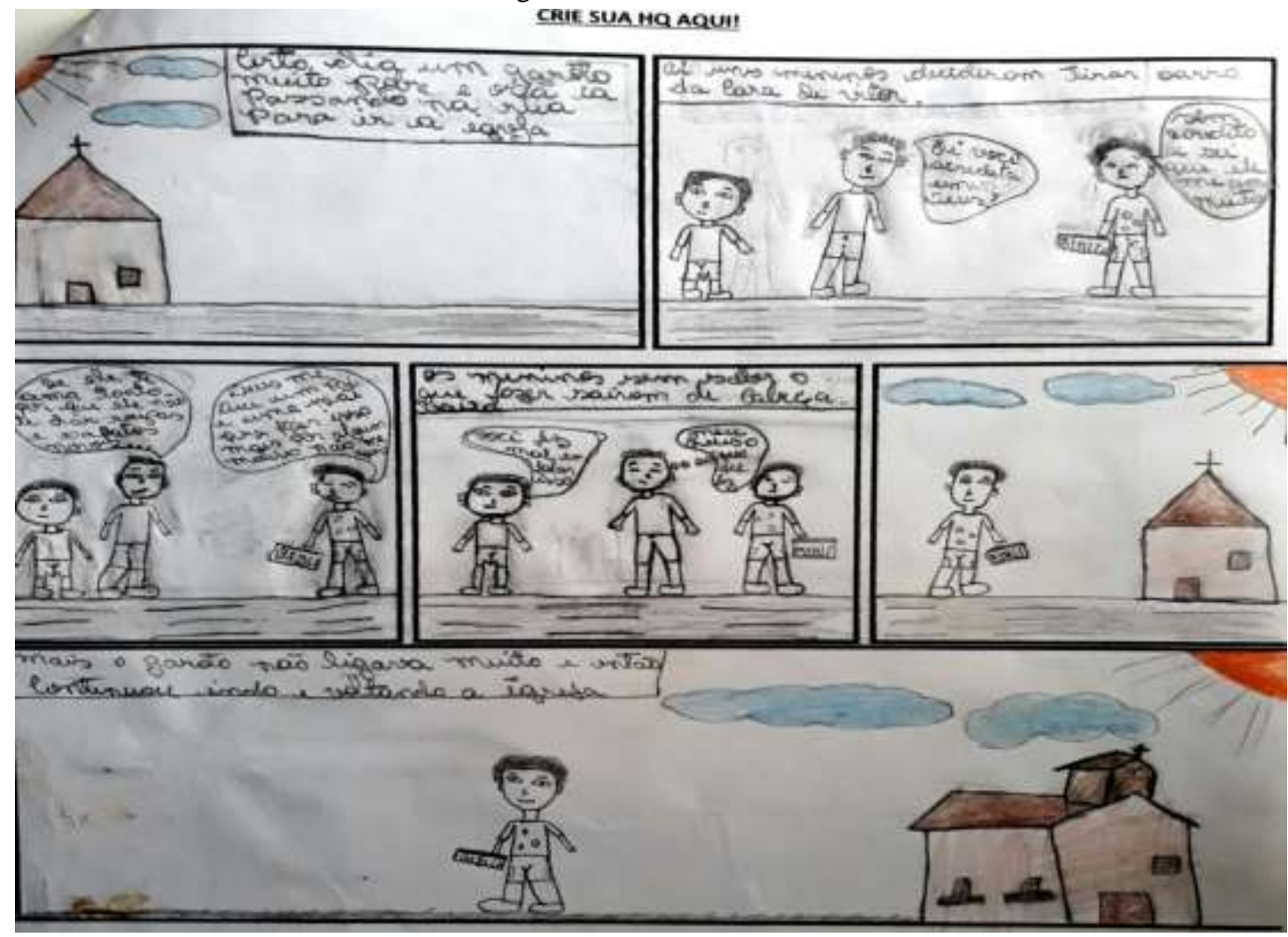

Fonte: Arquivo dos pesquisadores (2016).

Quadro 5 - Lista de Constatações sobre a T1 da aluna B1

- Pela leitura do texto, constatamos que a história tem a função de moralizar com o apelo bastante forte às questões religiosas e de cunho social (pobreza e pais que abandonam os filhos). A aluna conseguiu alcançar satisfatoriamente os objetivos nesta produção, porém é necessário observar algumas questões de melhoramento do texto.

- O contexto religioso em que a aluna estava inserida interferiu na escolha da temática.

- A aluna demonstra claramente a que público ela dirige seu texto.

- A aluna utiliza os elementos imagéticos que fazem parte do ambiente religioso: a igreja, a cruz e a Bíblia.

- Há a presença do narrador, que narra a história em $3^{a}$ pessoa (Ia, decidiram, saíram, etc.)

- O texto está adequado ao suporte.

- Houve contextualização prévia do que trataria a história

- A maioria dos balões foi empregado corretamente.

- A aluna inseriu a fala do narrador dentro do retângulo, local em que normalmente se encontra a fala do narrador das HQs.

- Faltou o título da história.

- O $5^{\circ}$ quadrinho não faz sentido.

- Apesar de curta, mas o desfecho dado à história foi interessante.

- A progressão temporal deve ser melhorada. Realizar a troca da palavra ai, $2^{\circ}$ quadrinho, por outra. 


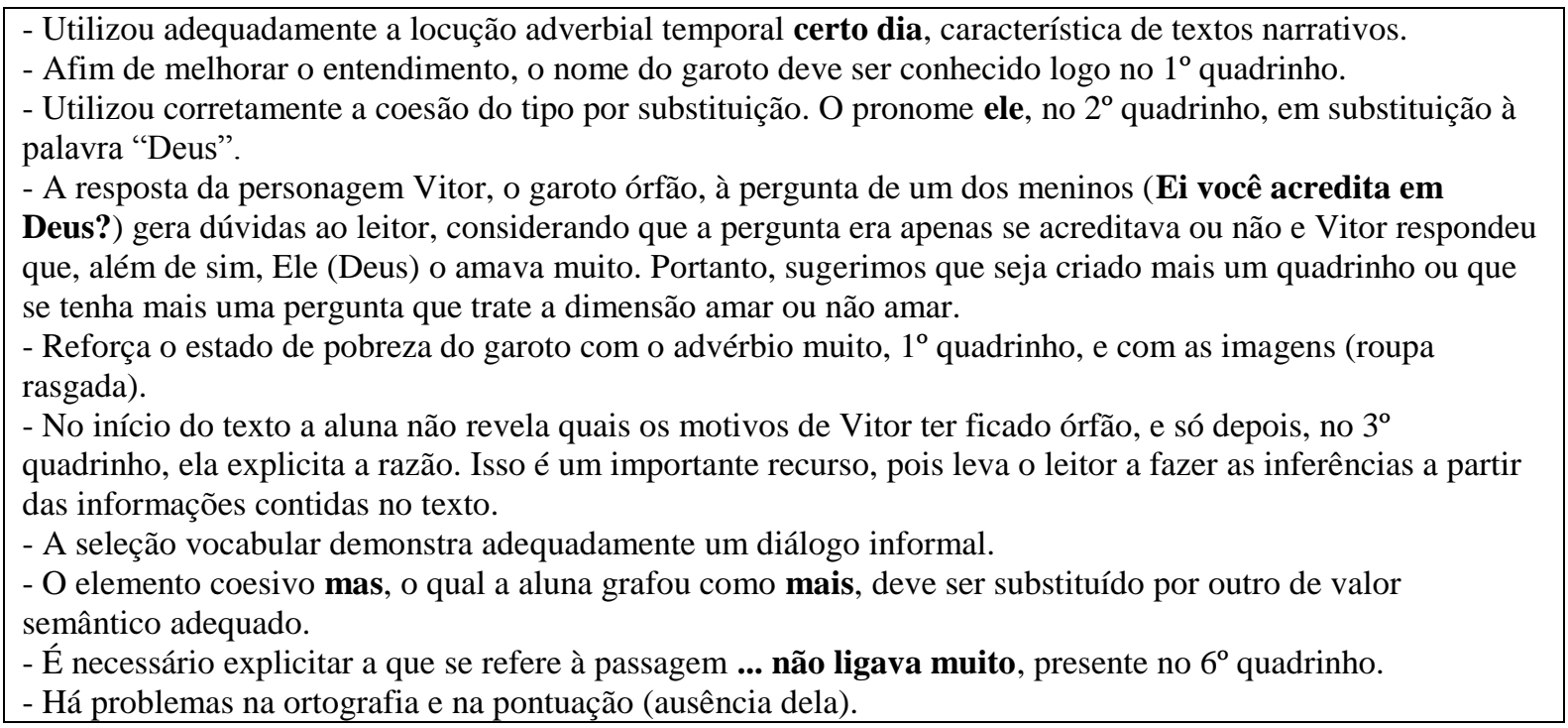
Fonte: Arquivo dos pesquisadores (2016)

A partir das constatações acima e das realizadas sobre os demais textos, sintetizamos, abaixo, o percentual de recorrência de inadequações por capacidade.

Tabela 1 - Percentual de inadequações por capacidade de linguagem

\begin{tabular}{|c|c|}
\hline CAPACIDADES & RECORRÊNCIAS DAS INADEQUAÇÕES \\
$\mathbf{\%}^{\mathbf{9}} \mathbf{1 0}$ \\
\hline Ação & 58,33 \\
\hline Discursivas & 100 \\
\hline Linguístico-discursivas & 83,33 \\
\hline
\end{tabular}

Fonte: Dados da Pesquisa (2016)

Ao analisar esses dados, concluímos que as inadequações se concentram principalmente nos aspectos tangíveis aos conhecimentos do gênero e à sequência textual mais presente nele; seguido de perto, das relativas à dimensão linguístico-discursiva. Para nós, esse resultado não é nenhuma surpresa, considerando que tanto os conhecimentos compartilhados naquela dimensão quanto nesta necessitam de um embasamento teórico estudado na escola. Por outro lado, as inadequações relativas à capacidade de ação possuem resultados mais satisfatórios, o que se justifica no fato de o sujeito mobilizá-la desde cedo, isto é, antes mesmo de ele se inserir no ambiente escolar.

Após as análises/correções, em casa, dos textos dos estudantes, retornamos à sala de aula a fim de promovermos, juntamente com eles, as intervenções. Essa primeira intervenção ocorreu oralmente, baseando-nos sempre no que já tínhamos constatado previamente.

\footnotetext{
${ }^{9}$ Inicialmente, estavam previstas treze produções iniciais, entretanto, um dos alunos faltou à aula nessa etapa, o que nos fez analisar e considerar para este estudo apenas doze.

${ }^{10}$ Para o cálculo dos percentuais não foram consideradas as inadequações ortográficas e de concordância.
} 
Revista Prática Docente - RPD

Confresa-MT. Volume 3. Número 2. Julho/Dezembro 2018.

Procuramos no momento da avaliação, em sala de aula, fazer intervenções/correções interativas pautadas no que afirma Teberosky (2000, p. 23):

não é só um meio, mas assume a qualidade de um objeto, quando os usuários não só interpretam ou repetem a mensagem, mas também a produz ou a contemplam; então $\mathrm{o}$ ato de escrever assume novas funções.

Em sala, explicamos aos estudantes como seria a dinâmica das intervenções: eles seriam organizados em dupla, e distribuídas as produções entre eles, em que cada um falaria do que achou do texto do colega. Perguntamos se todos estavam de acordo com a forma que iríamos proceder, foi então que alguns deles se opuseram, alegando que poderiam ser alvos de chacotas devido aos erros. Refletimos a respeito disso, e realmente vimos que fazia sentido o que foi alegado. Após um breve momento de negociação, decidimos, unanimemente, que cada aluno faria uma apresentação do seu texto e, em seguida, os outros colegas poderiam intervir, tendo sempre a cautela para não causar constrangimento no colega. Essa decisão, tomada por todos, foi importante porque os alunos, mesmo os mais tímidos, sentiram-se mais confiantes e perceberam que o projeto não era só para eles, mas também era deles.

Dentre as discussões realizadas nesse momento, destacamos a apresentação do texto do aluno A1. Ao apresentar seu texto, ele informou que sua história falava de uma girafa, chamada pintada, que havia fugido do zoológico e ansiava voltar para sua terra: a floresta. Ditas essas coisas, as quais não eram observáveis só pela leitura do texto, a aluna $\mathrm{C} 1$ perguntou a ele qual era o título da história. Antes de responder à pergunta da colega, outro aluno perguntou os motivos que levaram a pintada a fugir do zoológico. As respostas do aluno foram, respectivamente: A pintada fugiu e maus tratos e saudade da família dela. Os estudantes que levantaram os questionamentos propuseram as seguintes contribuições: $\mathrm{O}$ título ficaria melhor se fosse a fuga da girafa do zoológico e que ele (o aluno A1) pudesse colocar no seu texto os motivos da fuga da pintada. Perguntamos ao discente-autor o que ele achava das proposições dos colegas. O mesmo respondeu que com relação ao título não concordava com a sugestão, pois se ele fosse ler um tex to com esse título (A pintada fugiu), ele iria querer ler todo o texto para saber quem era essa pintada e de onde ela fugiu. Sobre a segunda contribuição, o aluno reconheceu que realmente era necessário evidenciar no texto os motivos que levaram a girafa a fugir do zoológico.

Outros discentes apontaram, sem muita segurança, que achavam que algumas das falas presentes no texto do aluno A1 eram do narrador e não da personagem. Essa observação, que foi nossa, mostrou a dificuldade que os alunos tinham em utilizar adequadamente as sequências 
Revista Prática Docente - RPD

Confresa-MT. Volume 3. Número 2. Julho/Dezembro 2018.

textuais (narrativa, descritiva, argumentativa, injuntiva e dialogal). Realizadas as intervenções por nós e pelos próprios alunos, solicitamos que os mesmos anotassem as que julgamos pertinentes, para que pudessem considerá-las na segunda versão do texto.

\subsection{ANÁLISE DAS PRODUÇõeS T2 E T3}

Ao compararmos a $\mathrm{T} 2$ com a $\mathrm{T} 1$, verificamos que houve um desenvolvimento significativo no tocante às capacidades verbais, especialmente as que mobilizam o conhecimento sobre o gênero, em que nove dos treze estudantes as utilizaram corretamente. Esse número se mostra mais positivo, se analisarmos apenas os que participaram da produção $\mathrm{T} 1$, onde nove dos doze promoverem refletidamente as adequações solicitadas nas intervenções sobre a T1. Todavia, com poucas exceções, as inadequações relativas à sequência textual narrativa persistiram na $\mathrm{T} 2$.

A seguir, estão as produções finais (T3) dos alunos A1 e B1 vetorizadas na plataforma Pixton.

Figura 3 - T3 do aluno A1 ( $1^{\mathrm{a}}$ parte $)$

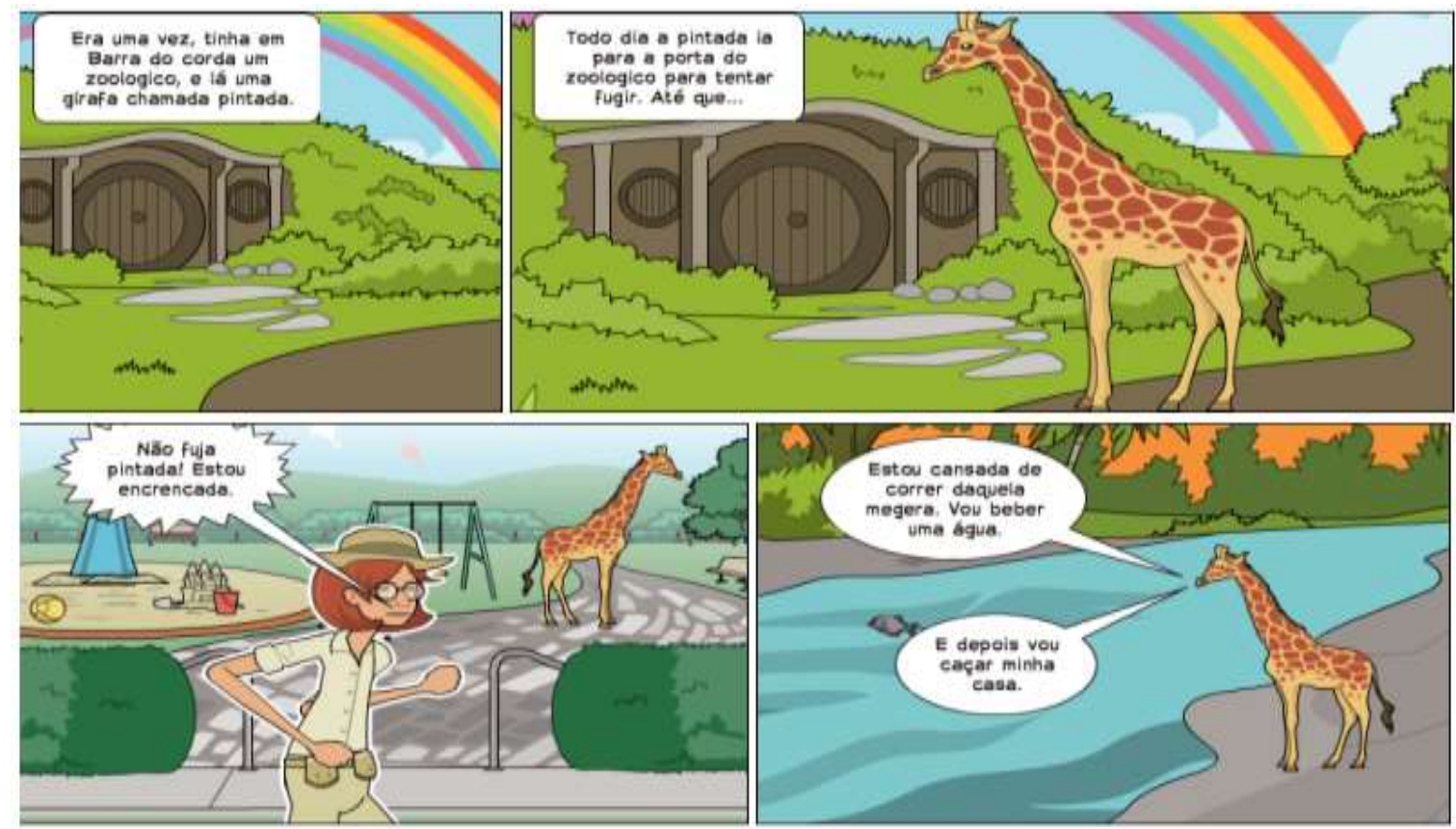

Fonte: Arquivo dos pesquisadores (2016). 
Figura 4 - T3 do aluno A1 (2 $2^{\mathrm{a}}$ parte $)$
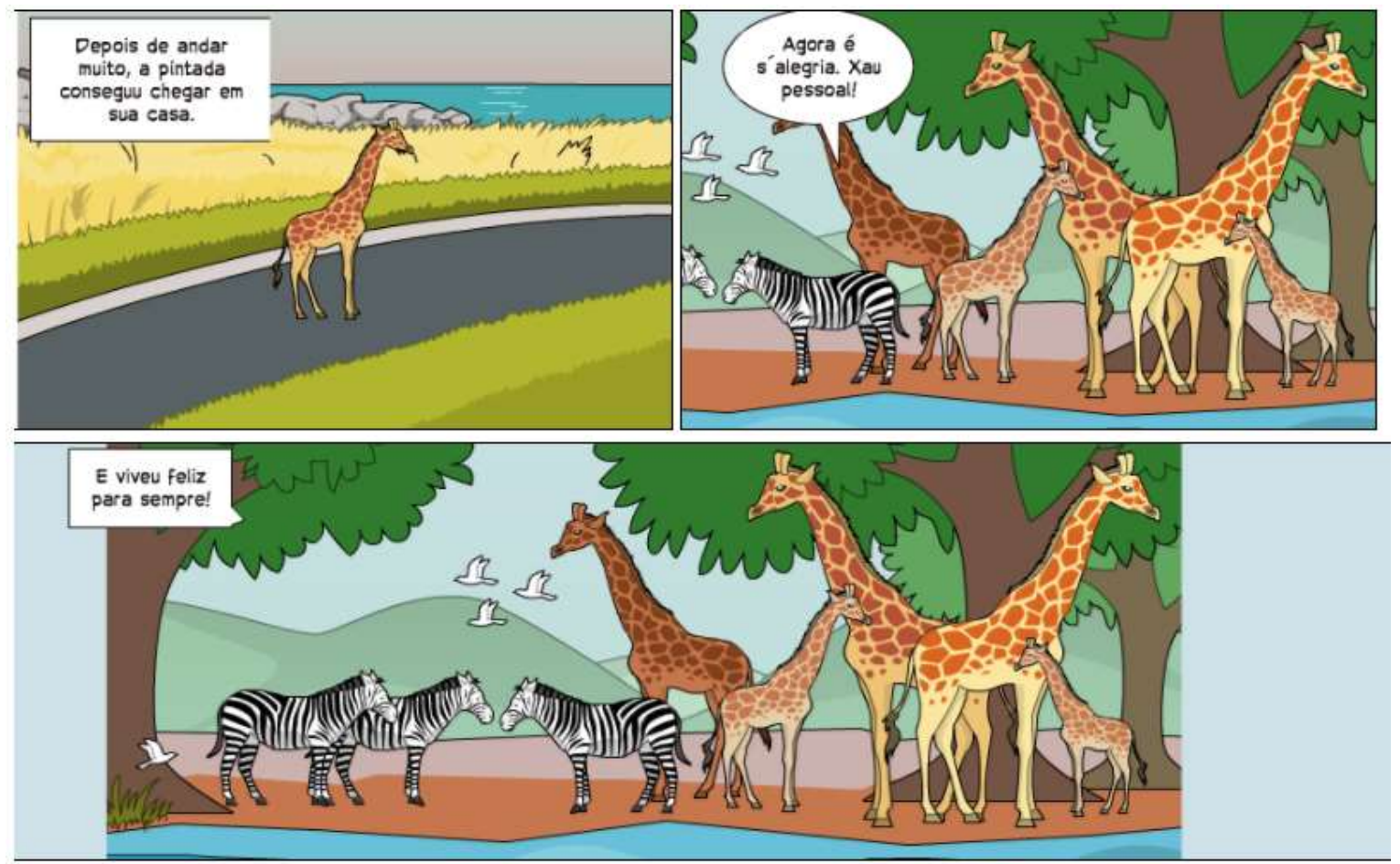

Fonte: Arquivo dos pesquisadores (2016)

Quadro 6 - Lista de Constatações sobre o texto T3 do aluno A1

- Houve contextualização prévia.

- O aluno não conseguiu articular melhor a história

- O texto apresentou os elementos de uma narrativa.

- O foco narrativo foi utilizado corretamente.

- A voz do narrador ficou evidente.

- Os balões foram usados corretamente.

- O título (A fuga da Pintada) atendeu ao objetivo de atrair o público-leitor.

- Não há figuras de linguagem.

- A sintonia entre o texto e as imagens foi melhorada.

- Apesar de pouca mudança, houve evolução quanto ao desfecho.

- Utilizou corretamente os verbos na fala das personagens.

- Poderia ter utilizado, em alguns casos, anáforas pronominais (Todo dia ela..., no $2^{\circ}$ quadrinho) e anáforas nominais (substituir a palavra Pintada por Girafa) a fim de evitar repetições.

- A seleção vocabular foi mais adequada (megera, agora é só alegria, Xau pessoal!)

- A coesão e coerência das cenas melhoraram.

- Utilizou marcadores temporais na voz do narrador (Era uma vez, Todo dia, Viveram Felizes, que quer dizer para sempre).

- Persistem os problemas de ortografia (acentuação, principalmente).

Fonte: Arquivo dos Pesquisadores (2016) 
Figura 5 - T3 da aluna B1

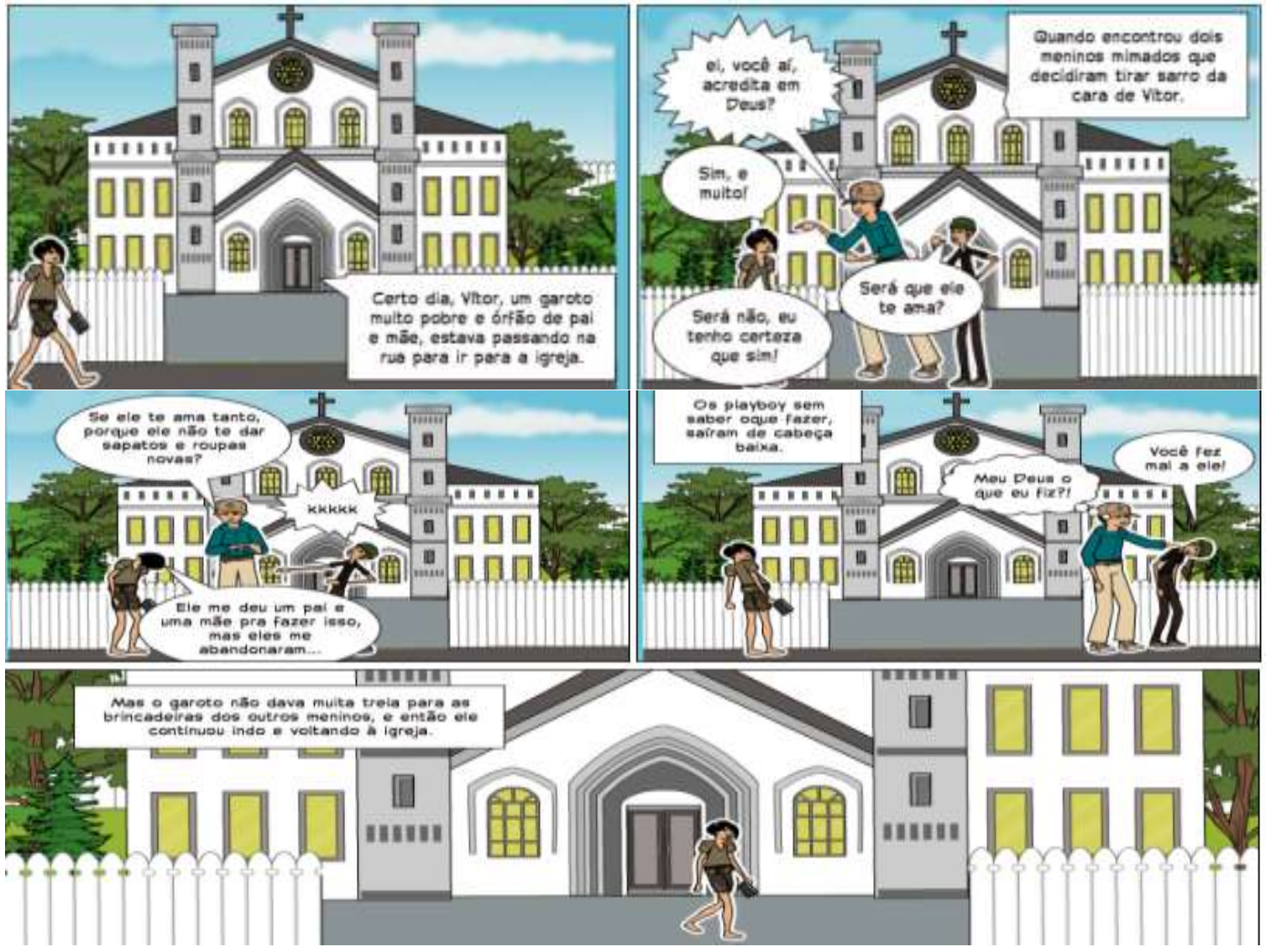

Fonte: Arquivo dos Pesquisadores (2016).

Quadro 7- Lista de Constatações sobre o texto T3 da aluna B1

- Pela leitura do texto, constatamos que a história tem a função de moralizar com o apelo bastante forte às questões religiosas e de cunho social (pobreza e pais que abandonam os filhos). A aluna conseguiu alcançar satisfatoriamente os objetivos nesta produção

- O contexto religioso em que a aluna estava inserida interferiu na escolha da temática.

- A aluna demonstra claramente a que público ela dirige seu texto.

- A aluna utiliza os elementos imagéticos, agora com expressões corporais mais fortes que fazem parte do ambiente religioso: a igreja, a cruz e a Bíblia.

- Há a presença do narrador, que narra a história em $3^{\mathrm{a}}$ pessoa.

- Melhorou a uniformização temporal (verbos)

- O texto está adequado ao suporte.

- Houve uma contextualização prévia do que trataria a história

- Os balões foram utilizados corretamente. Apenas no primeiro quadro, o balão parece ser de fala de personagem, mas, verificamos que ocorreu um erro na edição, o que é normal, já que a maioria desses estudantes não tinham tanto contato com softwares, inclusive, para alguns, essa foi a primeira experiência. - A aluna inseriu a fala do narrador dentro do retângulo, local em que normalmente se encontra a fala do narrador das HQs.

-Fez ajustes nas imagens e quadros, agora, estão em mais sintonia com o texto verbal.

- Apesar de curta, mas o desfecho dado à história foi interessante.

- Os elementos icônicos foram melhores trabalhados. Nesse aspecto, o programa Pixton, que possui mais recursos gráficos, ajudou bastante.

- A progressão temporal foi melhorada, à medida que uniformizou o tempo verbal.

- Utilizou adequadamente marcadores temporais na fala do narrador: certo dia, quando.

- Identificou a personagem principal, explicando corretamente, por meio de um aposto, quem era ela.

- Utilizou anáforas pronominais (ele) e nominais (playboy).

- Tornou o texto do $2^{\circ}$ mais compreensível. 
- Reforça o estado de pobreza do garoto com o advérbio muito, $1^{\circ}$ quadrinho, e com as imagens (roupa rasgada).

- No início do texto a aluna não revela quais os motivos de Vitor ter ficado órfão, e só depois, no $3^{\circ}$ quadrinho, ela explícita a razão. Esse é um importante recurso, pois leva o leitor a fazer as inferências a partir das informações contidas no texto.

- A seleção vocabular demonstra adequadamente um diálogo informal (ei, aí, trela, playboy).

- Reorganizou o texto do último quadrinho, o que deu sentido ao conectivo mas.

- Corrigiu a maioria dos casos de erros de ortografia.

Fonte: Arquivo dos Pesquisadores (2016).

Ao compararmos as constatações da produção T1 com as da T3, concluímos que a maioria dos alunos conseguiu melhorar o uso das suas capacidades de linguagem (ação, discursivas e linguístico-discursivas). Os resultados dessa evolução, baseados na recorrência das inadequações por capacidade, estão no gráfico abaixo.

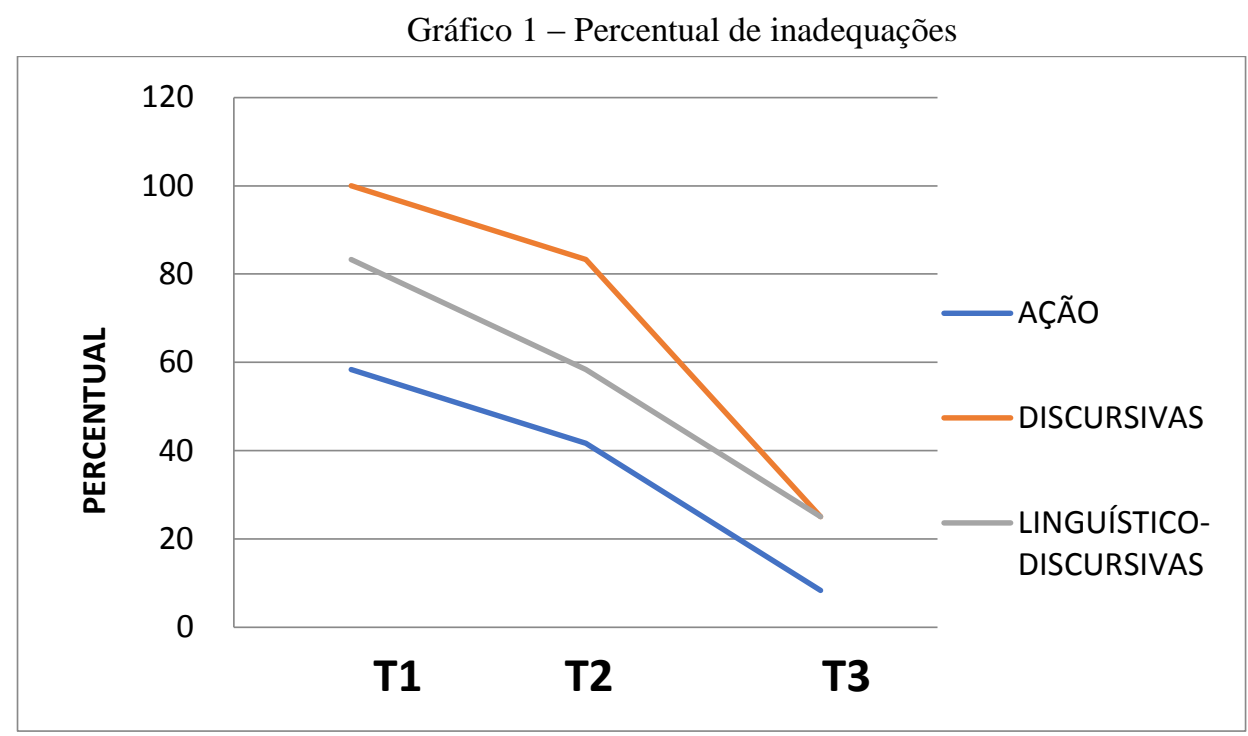

Fonte: Arquivo dos Pesquisadores (2016).

Segundo Dolz, Noverraz e Schneuwly (2004, p. 87), os módulos servem para “[...] trabalhar os problemas que apareceram na primeira produção e dar aos alunos os instrumentos necessários para superá-los”. Nessa perspectiva, os módulos que planejamos alcançaram os objetivos propostos, pois os resultados das análises sobre as produções textuais (T2 e T3), as quais foram realizadas logo após a execução de cada módulo, revelaram que houve progresso nas mesmas, isto é, as inadequações verificadas anteriormente foram progressivamente sendo superadas à medida que executávamos cada módulo.

O módulo I, que abordou as dimensões de ação e parte das discursivas, deu aos alunos subsídio suficiente para que a segunda versão do texto (T2) não contivesse todas as inadequações relativas às duas primeiras capacidades, onde a ocorrência de inadequações caiu 
Revista Prática Docente - RPD

Confresa-MT. Volume 3. Número 2. Julho/Dezembro 2018.

de 58,33\% (Capacidade de Ação), em T1, para 41,66 \%, em T2. O mesmo movimento, que foi descendente, ocorreu na dimensão discursiva, em que inicialmente todos os alunos (100\%) apresentaram dificuldades, e na T2, apenas $83,33 \%$. Esse resultado foi mais proeminente na T3, em que verificamos que apenas $25 \%$, o que correspondem a três alunos, não conseguiram sanar integralmente as dificuldades nessa dimensão.

\section{CONSIDERAÇÕES FINAIS}

As análises aqui realizadas ratificam que a linguagem ocorre sempre por meio de textos, orais ou escritos, formais ou informais, o que nos faz insistir que "o tex to é um objeto complexo que envolve não apenas operações linguísticas como também cognitivas, sociais e interacionais" (KOCH, 2006, p.15). Dessa forma, nas atividades de produção de um texto é necessário considerar também, além dos conhecimentos da língua, os conhecimentos de mundo, da cultura, e das formas de interação social.

Sobre os resultados alcançados, foi possível verificar o avanço na produção textual dos alunos no tocante às capacidades de ação, discursivas e linguístico-discursivas. No início do projeto, a recorrência de inadequações em cada uma dessas capacidades era, respectivamente, $58,33 \%, 100 \%$ e 83,33 \%. Após as intervenções, observamos que na T3 as recorrências das inadequações reduziram drasticamente para, respectivamente, $8,33 \%, 25 \%$ e $25 \%$.

Também fica notório que o trabalho docente com a produção textual em sala exige planejamento e estudo sobre as potencialidades que cada gênero textual apresenta, a fim de aproveitá-las, enquanto produto de ensino.

Por fim, acreditamos que este trabalho não traz a fórmula mágica para a solução dos problemas analisados, mas aponta um dos vários caminhos que podemos seguir cotidianamente, em sala de aula, para reduzir a distância abissal que existe entre o que está na teoria e na prática.

\section{REFERÊNCIAS}

BAKHTIN, M. Estética da criação verbal. 6ª ed. São Paulo: WMF Martins Fontes, 2011.

BRASIL. Ministério da Educação e Cultura. Parâmetros curriculares nacionais: Primeira parte: língua portuguesa/ Secretaria de Educação Fundamental. Brasília: MEC/SEF, 1997.

DOLZ, J. e SCHNEUWLY, B. Gêneros orais e escritos na escola. Tradução e organização Roxane Rojo e Glaís Sales Cordeiro. Campinas, SP: Mercado de Letras, 2004.

GONCALVES, A. V. Gêneros Textuais na Escola: da compreensão à produção. Dourados, MS: UFGD, 2010. 
KOCH, I. V. Desvendando os segredos do texto. 5a Edição. São Paulo: Cortez, 2006.

MARCUSCHI, L. A. Produção textual, análise de gêneros e compreensão. São Paulo: Parábola Editorial, 2008.

MENDONÇA. Márcia Rodrigues de Souza. Um gênero quadro a quadro: a história em quadrinhos. In: DIONISIO, A. P.; MACHADO, A.R.; BEZERRA, M. A. (orgs.). Gêneros Textuais e Ensino. São Paulo: Parábola Editorial, 2010. p.19 - 38.

ROJO, R. Gêneros do discurso e gêneros textuais: questões teóricas e aplicadas. In:

MEURER, J. L.; BONINI, A.; MOTTA-ROTH, D. Gêneros: teorias, métodos, debates. São Paulo: Parábola, 2005. p. 18.

TEBEROSKY, A. Aprendendo a escrever: perspectivas psicológicas e implicações educacionais. Tradução de Cláudia Schilling. 3. ed. São Paulo: Ática, 2001.

Recebido em: 19 de junho de 2018. Aprovado em: 25 de novembro de 2018. 